\title{
Area Under First Moment Curve
}

National Cancer Institute

\section{Source}

National Cancer Institute. Area Under First Moment Curve. NCI Thesaurus. Code C85536.

The area under the curve of a plot that graphs a discrete distribution of data calculated from a set of concentration-time data. 